\title{
Transport Safety (Motorcycle) \\ 01 THE GROWING USE OF MOTORCYCLES FOR COMMERCIAL TRANSPORT AND TRAFFIC SAFETY IN GHANA
}

doi:10.1136/injuryprev-2012-040590s.1

P Agyekum-Boamah. National Road Safety Commission Ghana

Background The use of motorcycles for commercial transport is an underground economy spreading in Ghana with traffic safety problems.

Aims and Objectives To verify the extent of traffic safety challenges from the use of motorcycle for commercial transport.

Methods Field surveys were conducted with the 200 operators and 100 users of the services through random sampling in two urban centres and a rural community in the Greater Accra, Volta and Upper East Regions of Ghana using questionnaires.

Results The illegal operation of this mode of transport is increasing at a rate of about 100 times that of conventional vehicular commercial transport due to affordability at $80 \%$ cheaper and higher returns at $20 \%$. Safety issues relate to violation of insurance coverage, improper clothing and non use of helmets. More than $50 \%$ of the operators have been involved in traffic crashes and $80 \%$ have had it more than once. Fatality rate is about $10 \%$, injury rate is $77.6 \%$ wit maiming of victims. Users still patronise it due to affordability, availability speed and convenience. Effective enforcement will be by education, increased taxes on motorcycles, stiffer penalties for offenders and provision of alternate employment for operators.

Significance The practice will grow along with related problems if the ban on it is not effectively enforced. However the effectiveness of this will depend on addressing current problems with conventional commercial transport services in the country. 